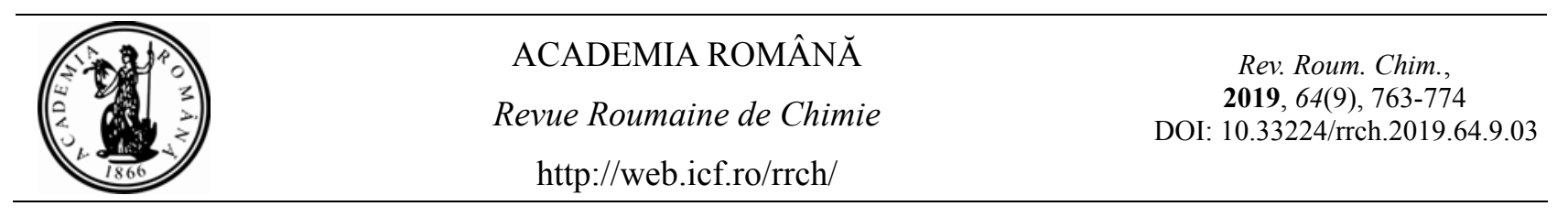

\title{
AMPEROMETRIC SENSING OF ORGANOPHOSPHORUS PESTICIDES BASED ON COVALENTLY ATTACHED MULTILAYER ASSEMBLIES OF DIAZO-RESIN, PRUSSIAN BLUE SINGLE-WALLED CARBON NANOTUBES, AND ACETYLCHOLINESTERASE
}

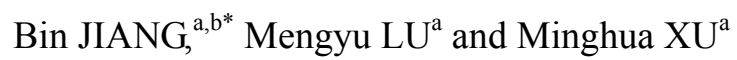 \\ ${ }^{a}$ College of Urban and Environmental Science, Northwest University, 1 Xuefu Ave., Chang'an District, Xi'an, 710127, \\ haanxi Province, China \\ ${ }^{\mathrm{b}}$ Shaanxi Provincial Key laboratory of earth surface system and environmental carrying capacity, Northwest University, \\ 1 Xuefu Ave., Chang'an District, Xi'an, 710127, Shaanxi Province, China
}

A novel organophosphorus pesticides (OPs) biosensor was fabricated based on electrostatic self-asembly in combination with in situ photo-cross-linking of acetylcholinesterase (AChE) on prussian blue (PB) deposited on the single-walled carbon nanotubes (PB-SWCNTs) backbone. The biosensor showed high sensitivity in the linear concentration range from $1.0 \times 10^{-6}$ to $10 \times 10^{-12} \mathrm{~g} \cdot \mathrm{L}^{-1}$, and the detection limit of malathion and methyl parathion were $3.11 \times 10^{-13} \mathrm{~g} \cdot \mathrm{L}^{-1}$ and $1.88 \times 10^{-13} \mathrm{~g} \cdot \mathrm{L}^{-1}$, respectively. In addition, the developed biosensor demonstrated to be highly reproducible with R.S.D. values of $4.59 \%$ for 5 successive amperometric calibrations using the same surface. When detecting malathion in real samples, the recoveries for the AChE biosensor ranged from $96 \%-105 \%$, indicating that this had excellent potential for practical application. More importantly, the results exhibited that thus method greatly improved biosensors stability in comparison with electrostatic interaction attributed to the conversion of weak ionic bonds to strong covalent ones for enzyme immobilization by the proposed strategy. It was a simple, cheap and table method to detect OPs and this method might pave the way for the sensitive, simple detection of different analytes without the need for expensive instrumentation.

\section{INTRODUCTION}

Organophosphorus pesticides (OPs) are widely used in agricultural fields in order to improve the quality and the quantity of crop. ${ }^{1-3}$ These processes always result in the presence of pesticide residue in fruits and vegetables, which are harmful to human health such as central nervous system, eventually leading to respiratory paralysis and even to

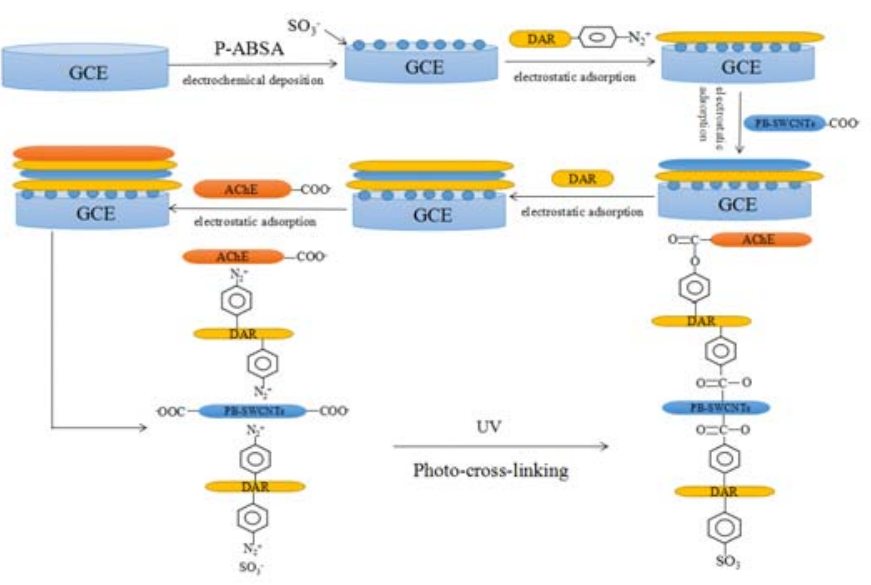

death. ${ }^{4,5}$ Moreover, OPs cause the main source of diffuse pollution in groundwater ${ }^{6}$ which can lead to contamination of soil, water systems and atmosphere. $^{7-9}$ Therefore, there is an increasing requirement to develop a reliable, rapid and highly sensitive assay for simultaneous determination of OPs to facilitate the risk assessment. Nowadays, there are many techniques which can be used to detect OPs including liquid chromatography, ${ }^{10}$ 
ultrahigh performance liquid chromatographytandem mass spectrometry ${ }^{11}$ and gas chromatography. ${ }^{4}$ However, there still are some disadvantages in detection work such as expensive instruments, the requirement of well-trained operators, and complicated pretreatments of samples and so on. ${ }^{12,13}$ To solve these problems, biosensors have been developed gradually because electrochemical detection is a kind of simpler, faster, and more cost-effective method which can achieve the environmental monitoring requirements. So the biosensor is widely used in the rapid detection of pesticide residues.

Enzymes have been widely used in the biochemical, pharmaceutical, biomedical and industrial fields. Among them, electrochemical biosensors based on enzymes have attracted attention because their properties have high sensitivity, rapid response and portability. ${ }^{14}$ Acetylcholinesterase (AChE) biosensors have shown exact results in OPs detection and enzyme activity is directly related to a quantity of pesticide. ${ }^{15}$ In the process, thiocholine is produced during the interaction of the acetylthiocholine chloride (ATCl) with $\mathrm{AChE}$ and the thiocholine detection is used to assess AChE activity in the presence of Ops. ${ }^{16,17}$ Therefore, it is a research focus of electrochemical biosensor based on AChE for improving the electrochemical behaviours of the biosensor. ${ }^{18}$

Single-walled carbon nanotubes (SWCNTs), which have good electrical conductivity characteristics and large superficial area, are a truly molecular entities and have unparalleled properties such as high mechanical strength and chemical stabilities. ${ }^{19,20} \mathrm{~PB}$ is a mixed cyanide complex and has the unique properties, such as synthetic versatility and the bridging cyanide ligands. $\mathrm{PB}$ is similar to cross-linked organic polymers which had stable structure and electrochemical reversibility, so it can be used as an electron exchange medium. PB functionalizes on the SWCNTs, directly causing the effect on electron transfer ${ }^{21}$ and the low-potential electron transfer mediation. ${ }^{22} \mathrm{~PB}-$ SWCNTs can act as a low-potential redox mediator and electron transfer facilitator. Meanwhile, the PB-SWCNTs are highly three-dimensional porous, providing a substrate for the further assembly of large amounts of diazo-resin (DAR) and enzymes on the PB-SWCNTs backbone. ${ }^{23}$

This paper fabricates a novel AChE biosensor in combination with situ photo-cross-linking of AChE and DAR on PB-SWCNTs backbone. DAR containing diazo group is a good cross-linking agent because the positive carbon ions produced by the decomposition of the diazo group can react with hydroxyl and generate ether bone. The film of $\mathrm{AChE}$ is an ideal material and this film is sensitive to OPs. This simple and environmentally friendly film is suspected to present a large surface area for AChE adsorption and can enhance electrontransfer as well as the signal of electro-oxidation of ATCl. Encouragingly, this method may open up new opportunities for fast, simple and sensitive analysis of OPs.

\section{RESULTS AND DISCUSSION}

\section{Characterization of the PB-SWCNTs}

UV-vis absorption spectra were performed to confirm the formation of the PB-SWCNTs nanocomposites. Fig. 1 showed the UV-vis absorption spectra of SWCNTs(a); PB(b); PBSWCNTs nanocomposites(c). In the case of SWCNTs, no obvious absorbance could be found (Fig. 1a). PB nanoparticles, in contrast, yielded a single band around $710 \mathrm{~nm}$ (Fig. 1b), similar to the previous articles. ${ }^{24}$ The absorbance peak appearing at $700 \mathrm{~nm}$ in the UV-vis absorption spectra (Fig. 1c) of the composites confirmed the formation of PB deposited SWCNTs (PB-SWCNTs). ${ }^{25}$ In the micro structure of $\mathrm{PB}$, the ferric ions were strongly to the carbon skeleton, as the bridging cyanide ligands and had the ability to bridge other ions. ${ }^{26}$ There had been reported on interaction between SWCNTs and PB through $\pi-\pi$ interaction ${ }^{27}$ and electrostatic attraction. ${ }^{28}$ The carbon atoms in the sidewall of SWCNTs and the $\mathrm{CN}$ of $\mathrm{PB}$ were conjugated and then they could act as electron acceptor and donor. Therefore, $\pi-\pi$ stacking interaction would occur between the sidewall of SWCNTs and the $\mathrm{CN}$ of $\mathrm{PB}^{29,30}$ In addition, cations in the PB (iron ions) might interact with anions in the SWCNTs (carboxyl moieties) through ionic interaction. ${ }^{31}$

\section{Cyclic voltammetry (CV)}

The deposition processes of various layers of DAR/PB-SWCNTs on GCE in $1 \mathrm{M} \mathrm{H} 2 \mathrm{SO} 4$ solutions were characterized by $\mathrm{CV}$ as shown in Fig. 2. It could be seen that the oxidation peak at $0.96 \mathrm{~V}$ and a reduction peak at $0.42 \mathrm{~V}$ of the region from -0.1 to $1.4 \mathrm{~V}$. Generally speaking, the 
fabrication procedure was adsorption of alternating layers of DAR/PB-SWCNTs/DAR on GCE, which was mainly caused by the electrostatic attraction between the positive charge on the top of DAR and negative charge on the top of PB-SWCNTs and sulfurous acid group from solution. The negatively charged SWCNTs and positively charged DAR possibly come up with mutual adsorption due to weak ion interaction between them. By CVs in $1 \mathrm{M}$ $\mathrm{H} 2 \mathrm{SO} 4$ solution, a gradual increase intensity of PB-SWCNTs/DAR multilayer films assembled as a function of deposition cycles (Fig. 2b-e), indicating the successful multilayer films coating on the electrode. Nevertheless, there was no current response seen at bare GCE in this region (Fig. 2a).

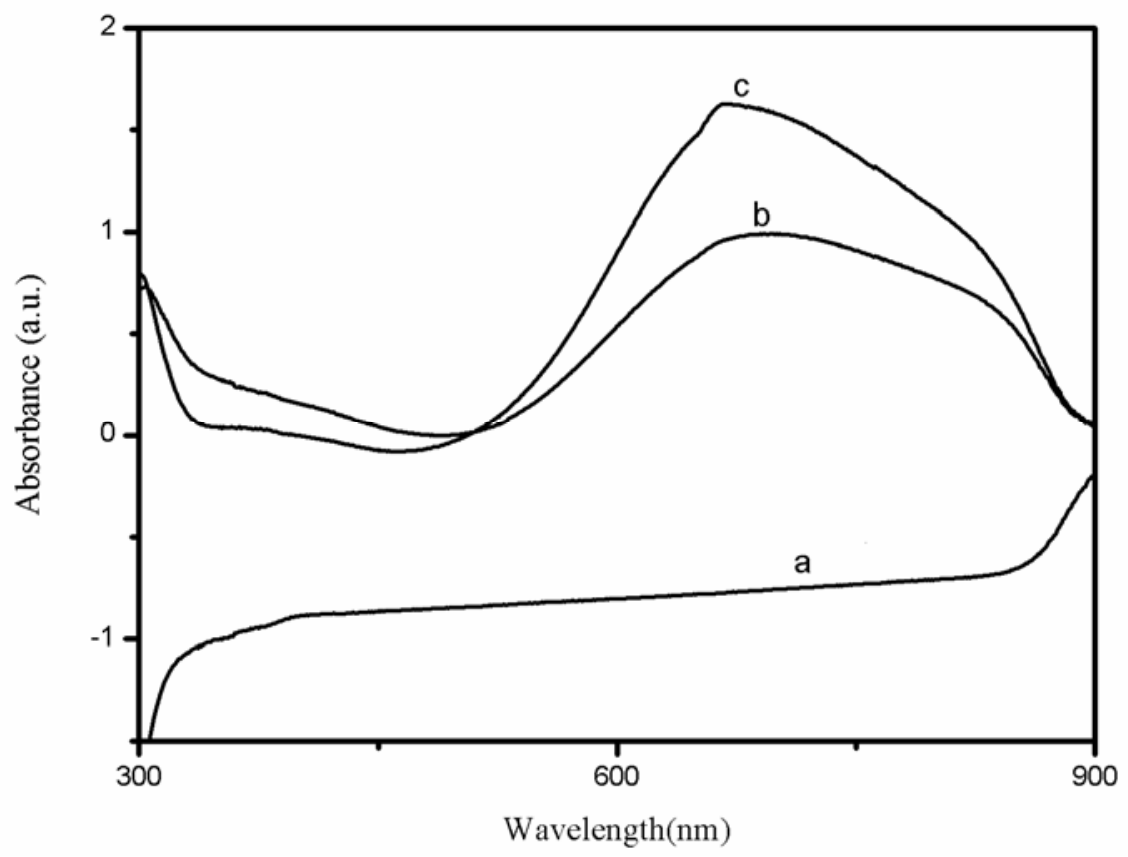

Fig. 1 - UV-vis absorption spectra of (a) SWCNTs, (b) PB, (c) PB-SWCNTs nanocomposites.

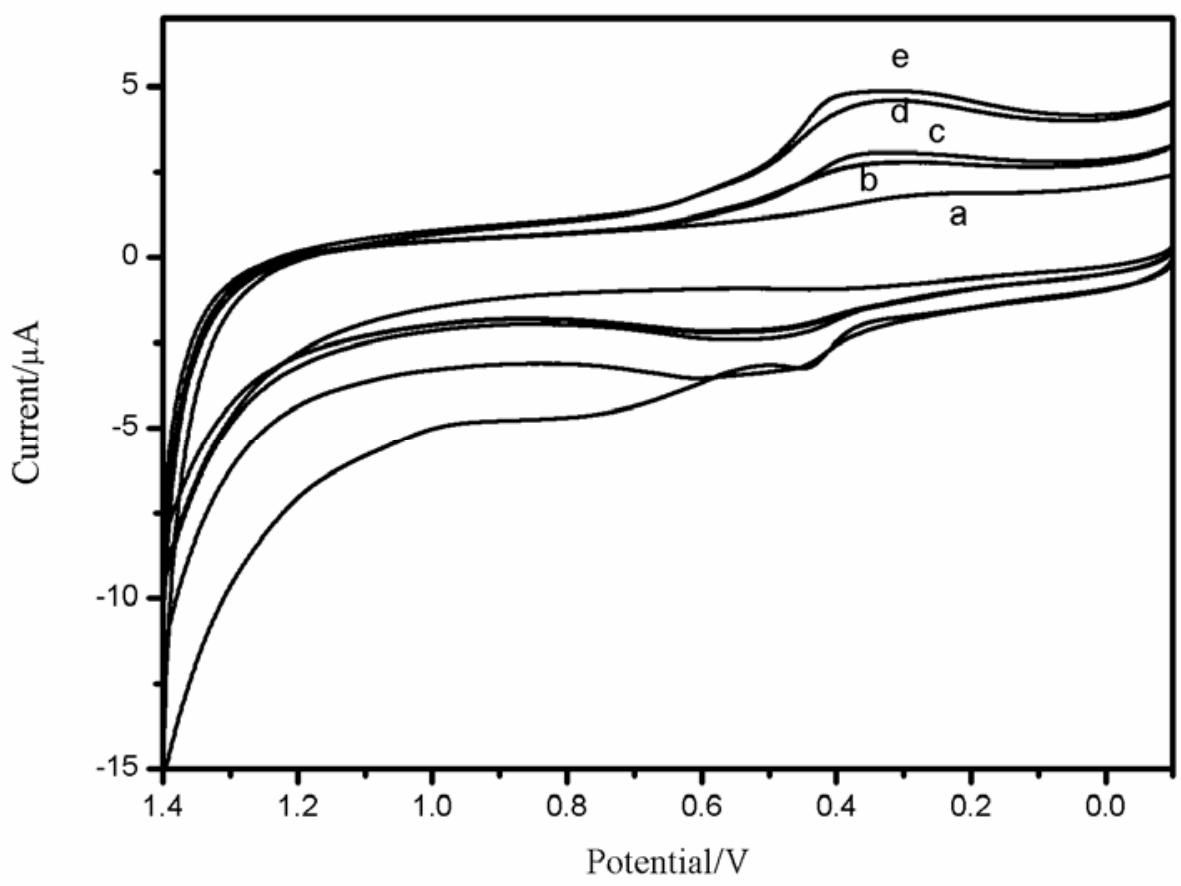

Fig. 2 - Cyclic voltammograms of: bare GCE (a); GCE/P-ABSA/DAR/PB-SWCNTs (b); GCE/P-ABSA/(DAR/PB-SWCNTs)2 (c); GCE/P-ABSA/(DAR/PB-SWCNTs)3 (d); GCE/P-ABSA/(DAR/PB-SWCNTs)4 and (e) in 1 M H2SO4 solution. Scan rate: 100 mV s-1. 


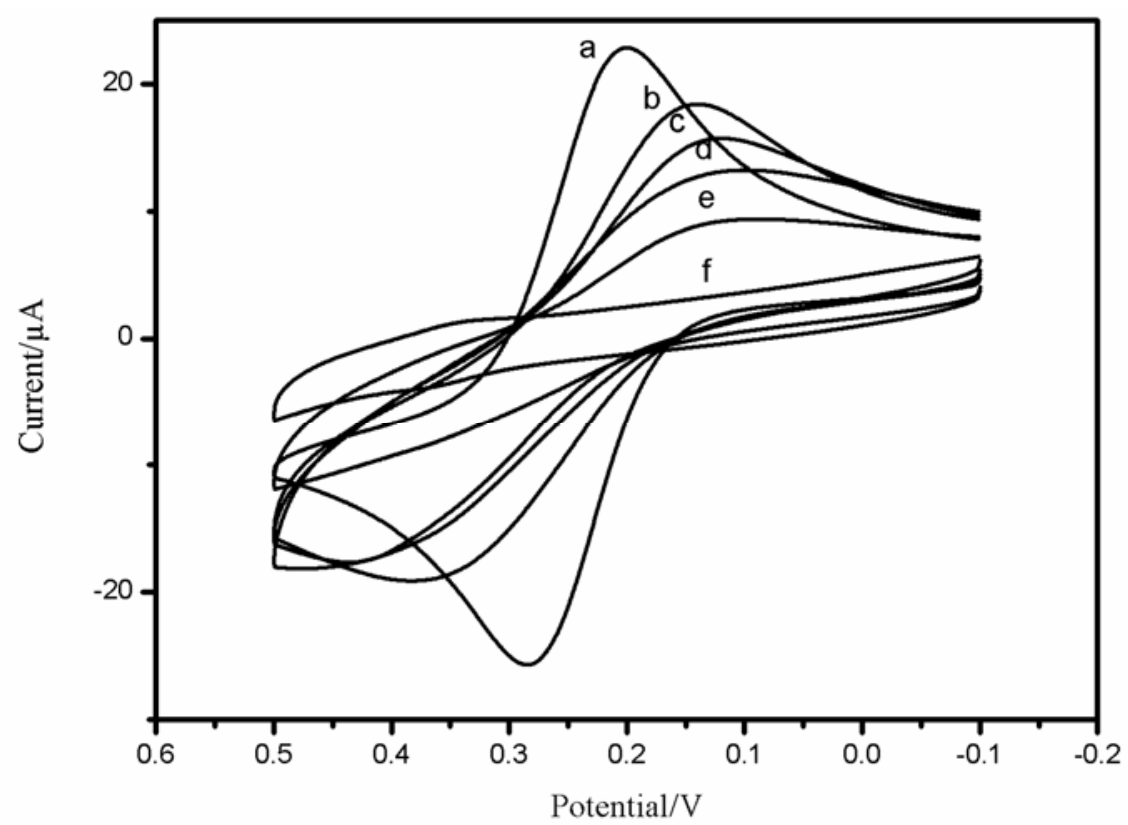

Fig. 3 - CVs of $1 \mathrm{mM} \mathrm{K3Fe[CN]6} \mathrm{and} 1 \mathrm{mM} \mathrm{K4Fe[CN]6} \mathrm{containing} 0.1 \mathrm{M} \mathrm{KCl}$ at: bare GCE (a); GCE/P-ABSA/(DAR/PB-SWCNTs)1 (b); GCE/P-ABSA/(DAR/PB-SWCNTs)2 (c); GCE/P-ABSA/(DAR/PB-SWCNTs)3 (d); GCE/P-ABSA/(DAR/PB-SWCNTs)4 (e) and GCE/P-ABSA(f). Scan rate: $100 \mathrm{~m}$ Vs-1.

The electrochemical behaviour of $\mathrm{K} 3 \mathrm{Fe}[\mathrm{CN}] 6$ solution at GCE surface modified with DAR/PBSWCNTs layers were investigated. It could be seen that $\mathrm{K} 3 \mathrm{Fe}[\mathrm{CN}] 6$ exhibited nearly reversible behavior on bare GCE in Fig. 3a. After fabricated with P-ABSA, the GCE surface was with many anions (S03-) to form an insulating layer. Insulating layer hindered the electronic transfer between $\mathrm{K} 3 \mathrm{Fe}[\mathrm{CN}] 6$ and the electrode, so there was nearly no current response in $\mathrm{K} 3 \mathrm{Fe}[\mathrm{CN}] 6$ (Fig. 3f). However, the redox peaks appeared again after modification with one layer of DAR/PB-SWCNTs, and it revealed that this film improved the electron transfer (Fig. 3b). But the current response was smaller than the bare electrode due to the presence of DAR and many anions (S03-) on the GCE surface. In addition, because DAR was not conductive, the reaction trend was decreasing for $\mathrm{K} 3 \mathrm{Fe}[\mathrm{CN}] 6$ with the increasing amount of DAR/PB-SWCNTs layers (Fig. 3c-e). All the current responses were smaller compared with the one layer of DAR/PB-SWCNTs electrode.

\section{Electrochemical impedance spectroscopy (EIS)}

EIS was an effective method to monitor the features of surface to understand the processes associated with the conductive electrode surface. Fig. 4 showed the EIS of bare GCE and GCE modified with P-ABSA and different layers of DAR/PB-SWCNTs in a solution of $5 \mathrm{mM}$
$\mathrm{Fe}(\mathrm{CN}) 63-/ 4-$ containing $0.1 \mathrm{M} \mathrm{KCl}$. As could be seen in Fig. 4a, the bare GCE exhibited an almost straight line and no obvious semicircle, indicating little electron transfer resistance existence. After GCE modified with a layer of P-ABSA, a big semicircle appeared at higher frequencies (Fig. 4b), which revealed the electron transfer resistance increased greatly. As shown in Fig. 4c, the semicircle diameter decreased sharply after modified with a layer of DAR/PB-SWCNTs. It was because of the existence of PB-SWCNTs. However, the semicircle diameter increased gradually with the increasing layer numbers of DAR/PB-SWCNTs (Fig. 4d-f). These data were in good agreement with CVs experiments. In addition, the semicircle diameter was uniformly increased with the increase of layer numbers, which implied that the process of assembling was continuous and uniform.

\section{Effect of potential scan rate}

The electrochemical behaviour of thus-prepared films at different scan rates in $0.1 \mathrm{M}$ PBS containing $2 \mathrm{mM}$ ATCl aqueous solutions were shown in Fig. 5. At scan rate of $20 \mathrm{mV} \mathrm{s}-1$, one cathodic peak could be seen at $0.63 \mathrm{~V}$. The presence of one cathodic peak indicated both surface and inner atoms of PB were involved in the redox reaction, forming stable films with SWCNTs through both $\pi-\pi$ and covalent interactions. ${ }^{29}$ With scan rates increasing, the cathodic peaks at $0.85 \mathrm{~V}$ 
gradually negative shift and the corresponding peak currents were linear proportional to the square root of the scan rates. It was found that the cathodic peak at $0.55 \mathrm{~V}$ due to the inner reaction of $\mathrm{PB}^{31}$ Besides, the cathodic peak at $0.63 \mathrm{~V}$ and 20 $\mathrm{mVs}-1$ of scan rate disappeared with the scan rates increasing. This could be due to the surface reaction of $\mathrm{PB}{ }^{25}$ The current peak of scan rate was examined under this conditions with a plot of logarithm of peak current (logIp) versus logarithm of scan rate $(\log v)$, giving a straight line with in the same scan rate range with a slope of 0.7007 (Inset. Fig. 5) closed to the theoretical value of 1.0, which was expected for an ideal reaction for the adsorption controlled electrode process. $^{32}$ This linear relationship was obtained as follows:

$$
\operatorname{LogIp}(\mu \mathrm{A})=0.7007 \log \mathrm{v}(\mathrm{mVs}-1)-0.1803
$$

$(\mathrm{R} 2=0.9533)$

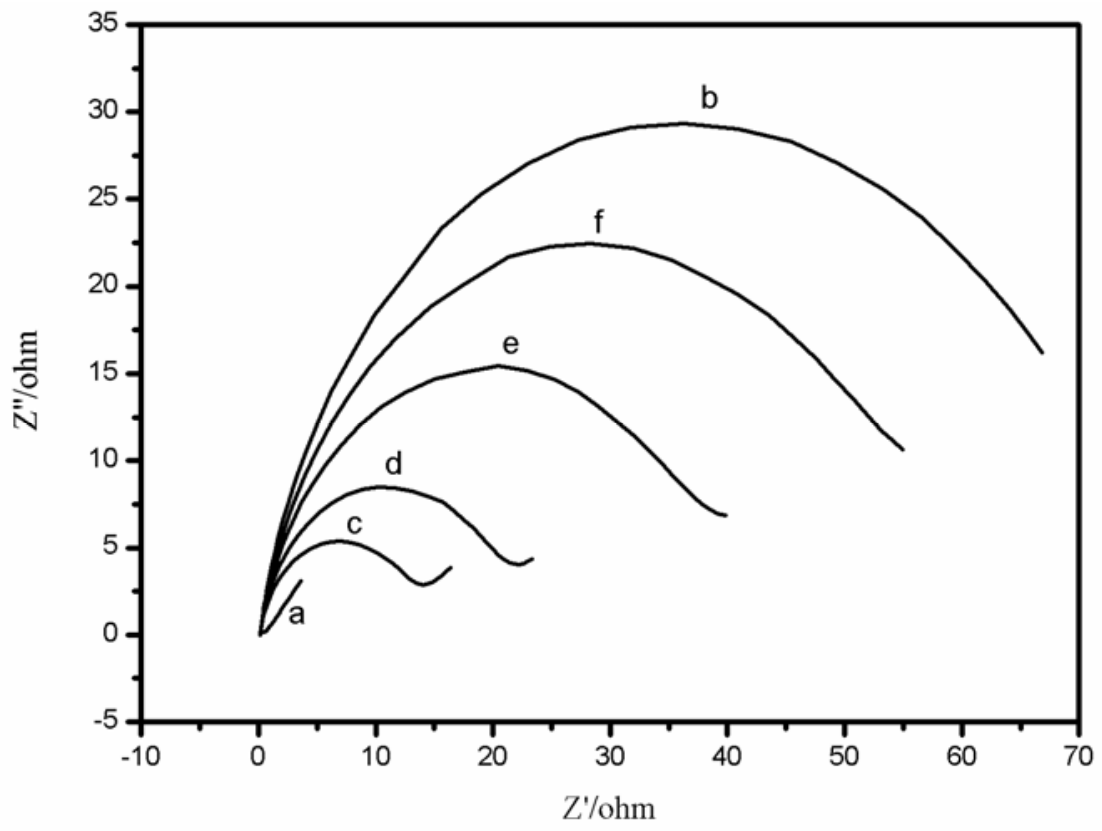

Fig. 4 - Complex impedance plots (Z' vs. Z" at 170mV vs. SCE) in $5 \mathrm{mM} \mathrm{Fe(CN)63-/4-} \mathrm{containing} 0.1 \mathrm{M} \mathrm{KCl}$ at: bare GCE (a); GCE/P-ABSA (b); GCE/P-ABSA/(DAR/PB-SWCNTs) (c); GCE/P-ABSA/(DAR/PB-SWCNTs)2 (d); GCE/P-ABSA/(DAR/PB-SWCNTs)3 (e) and $\mathrm{GCE} / \mathrm{P}-\mathrm{ABSA} /(\mathrm{DAR} / \mathrm{PB}-\mathrm{SWCNTs}) 4$ (f). The frequency range is 10-1-105 Hz.

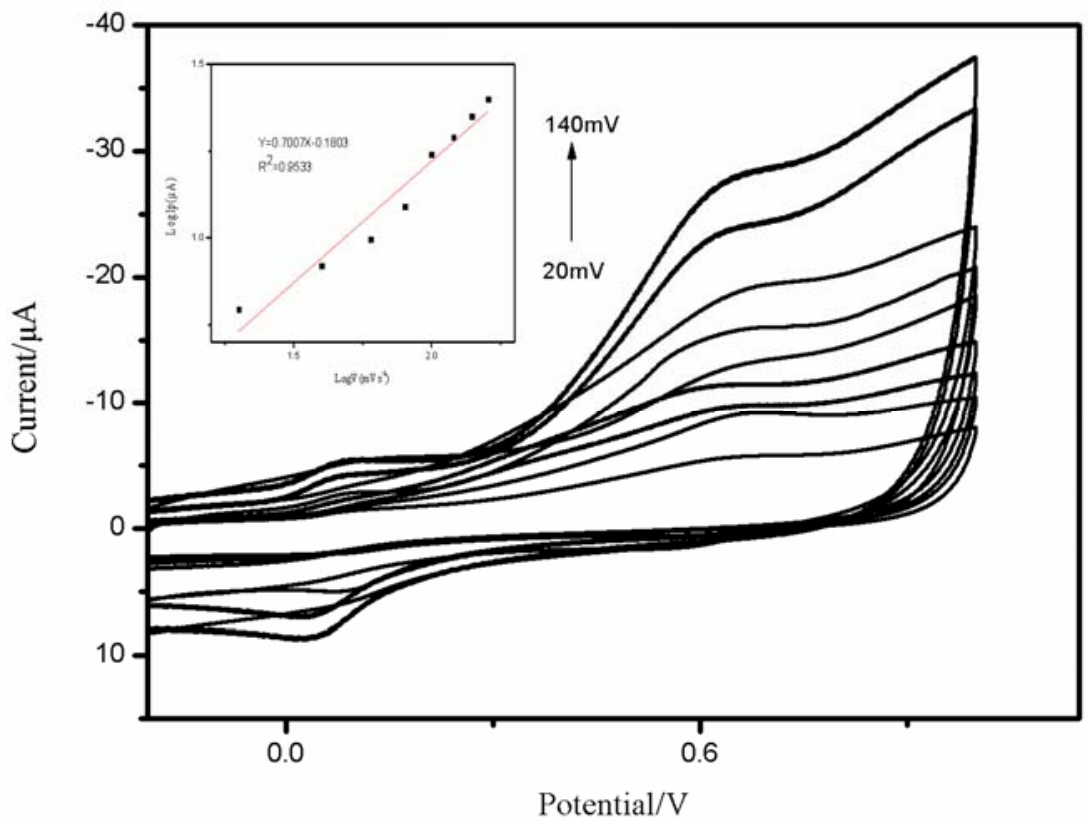

Fig. 5 - CVs of the AChE/DAR/PB-SWCNTs/DAR/P-ABSA/GCE at various scan rates (20 mV s-1 to $140 \mathrm{mV}$ s-1) in PBS (pH 5.5) containing $2 \mathrm{mM}$ ATCl. Insets: plot of logarithm of peak current versus logarithm of scan rate. 


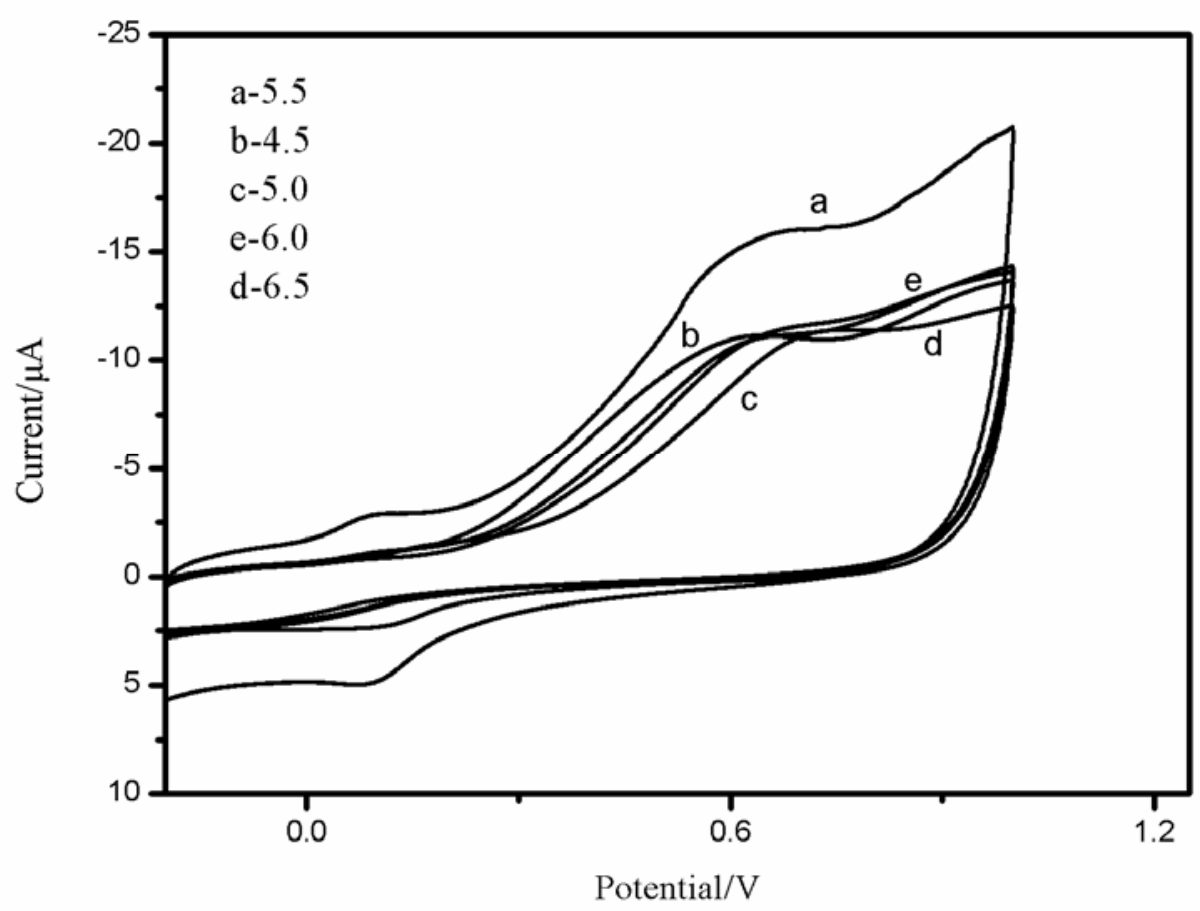

Fig. 6 - CVs of the AChE/DAR/PB-SWCNTs/DAR/P-ABSA/GCE

in $0.1 \mathrm{M}$ PBS containing $2 \mathrm{mM} \mathrm{ATCl}$ with the $\mathrm{pH}$ values varying from 4.5 to 6.5 .

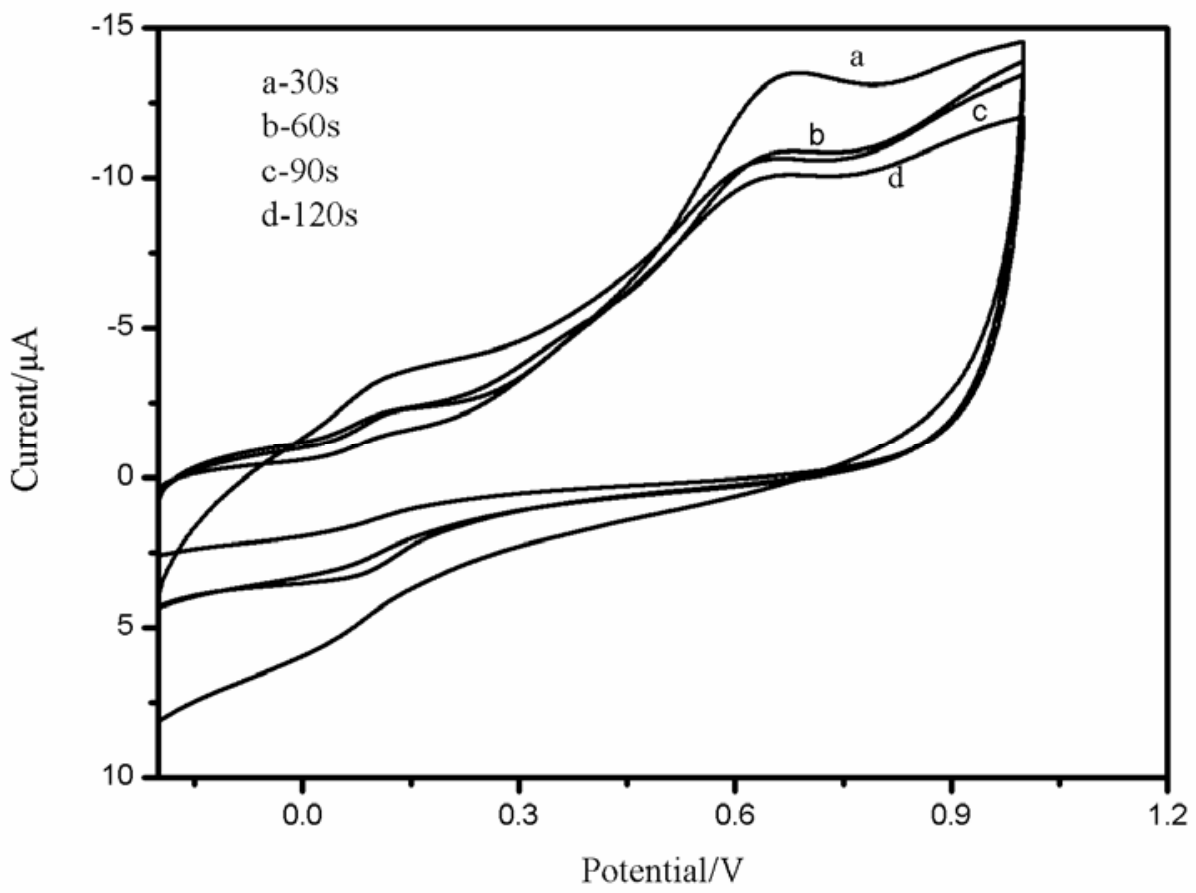

Fig. 7 - CVs of the AChE/DAR/PB-SWCNTs/DAR/P-ABSA/GCE

in $0.1 \mathrm{M}$ PBS ( $\mathrm{pH} 5.5$ ) containing $2 \mathrm{mM}$ ATCl. The UV-cross-linking times were $30 \mathrm{~s} / 60 \mathrm{~s} / 90 \mathrm{~s} / 120 \mathrm{~s}$.

\section{Selection of conditions}

\subsection{The effect of $\mathrm{pH}$}

To optimize the $\mathrm{pH}$ of PBS by CVs, the $\mathrm{pH}$ of PBS ranging from 4.5 to 6.5 were studied. Fig. 6 showed the trend in changes of the oxidation peak current with increasing $\mathrm{pH}$ of $\mathrm{PBS}$, and the $\mathrm{pH}$ reached a maximum at 5.5. It was found that the oxidation peak current increased with increasing $\mathrm{pH}$ of PBS, and reached a maximum at 5.5, then decreased with the following increase of the $\mathrm{pH}$. This phenomenon might be due to the presence of 
AChE, which isoelectric point was 5.6 and would be deactivated with improper $\mathrm{pH}$. Therefore, the $\mathrm{pH}$ 5.5 PBS was chosen as the supporting electrolyte for the detection.

\subsection{The effect of UV-cross-linking time}

The effect of the UV-cross-linking time on the peak current was studied in the range from 30 s to 120s. The results were shown in Fig. 7. The peak current on the AChE/DAR/PB-SWCNTs/DAR/PABSA/GCE increased with UV-cross-linking time at 30s. When the UV-cross-linking time was longer than 30 s, the peak current dropped slightly. This phenomenon was due to the decrease of the enzyme activity when prolonged exposure of the enzyme was produced under the long ultraviolet light, and the sensitivity of the biosensor would be decreased. Therefore, 30s was selected as the UV-cross-linking time.

\subsection{The effect of substrate concentration}

Substrate concentration change had a great influence on the enzyme reaction rate. This paper investigated the modified electrodes in $\mathrm{pH}$ 5.5, 0.1 $M$ in PBS, under the best condition for the influence of different concentration of ATCl response current signal, and the experimental results were shown in Fig. 8. ATCl concentration changed in 1-2 $\mathrm{mM}$ and the catalytic current increased with the increase of initial concentration.

When the ATCl concentration was $2 \mathrm{mM}$, the response current was the highest. When ATCl concentration was higher than $2 \mathrm{mM}$, however, the current decreased significantly with the increase of concentration. Because the increase in ATCl concentration caused a saturation of the active sites on enzyme, leaving fewer sites available for new molecules to bind, the peak current showed a decrease. Therefore, $2 \mathrm{mM}$ ATCl was selected as the substrate concentration to detect OPs.

\subsection{Inhibition activity of malathion and methyl parathion}

ATCl was hydrolyzed into thiocholine and acetate by AChE catalyzed reaction. ${ }^{16}$ Thiocholine detection was used to assess the inhibition of AChE activity in the presence of Ops. ${ }^{17}$ In this paper, malathion and methyl parathion were selected to detect enzyme inhibition rate. With increasing concentration of OPs (malathion and methyl parathion) in $10 \mathrm{~mL}$ PBS contained $2 \mathrm{mM}$ $\mathrm{ATCl}$, the peak of current was obviously declined, because the activity of AChE was declined. The peak of current was inversely proportional to the concentration of the OPs.

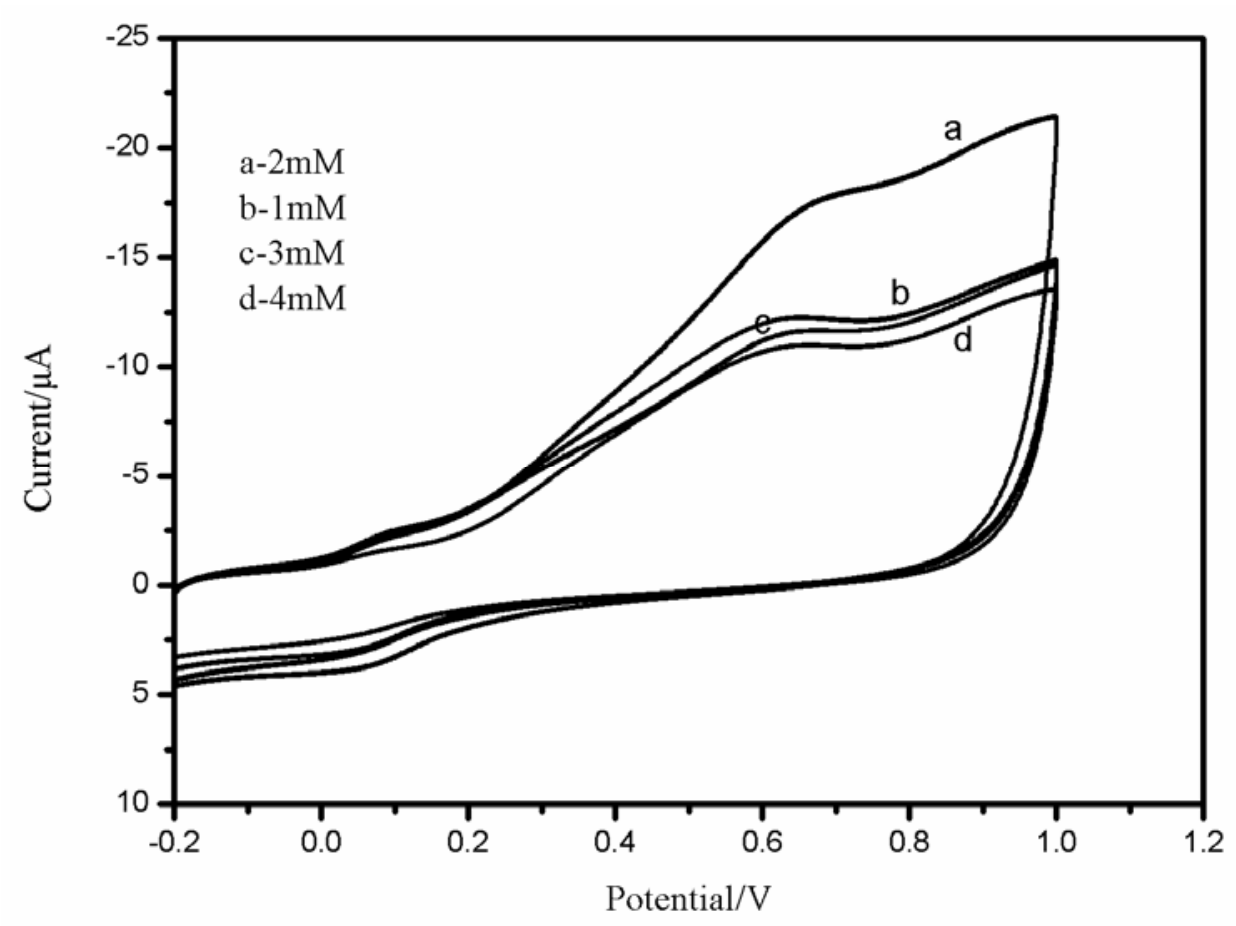

Fig. 8 - CVs of the AChE/DAR/PB-SWCNTs/DAR/P-ABSA/GCE in 0.1 M PBS (pH 5.5). ATCl concentrations are respectively $1 \mathrm{mM} / 2 \mathrm{mM} / 3 \mathrm{mM} / 4 \mathrm{mM}$. 


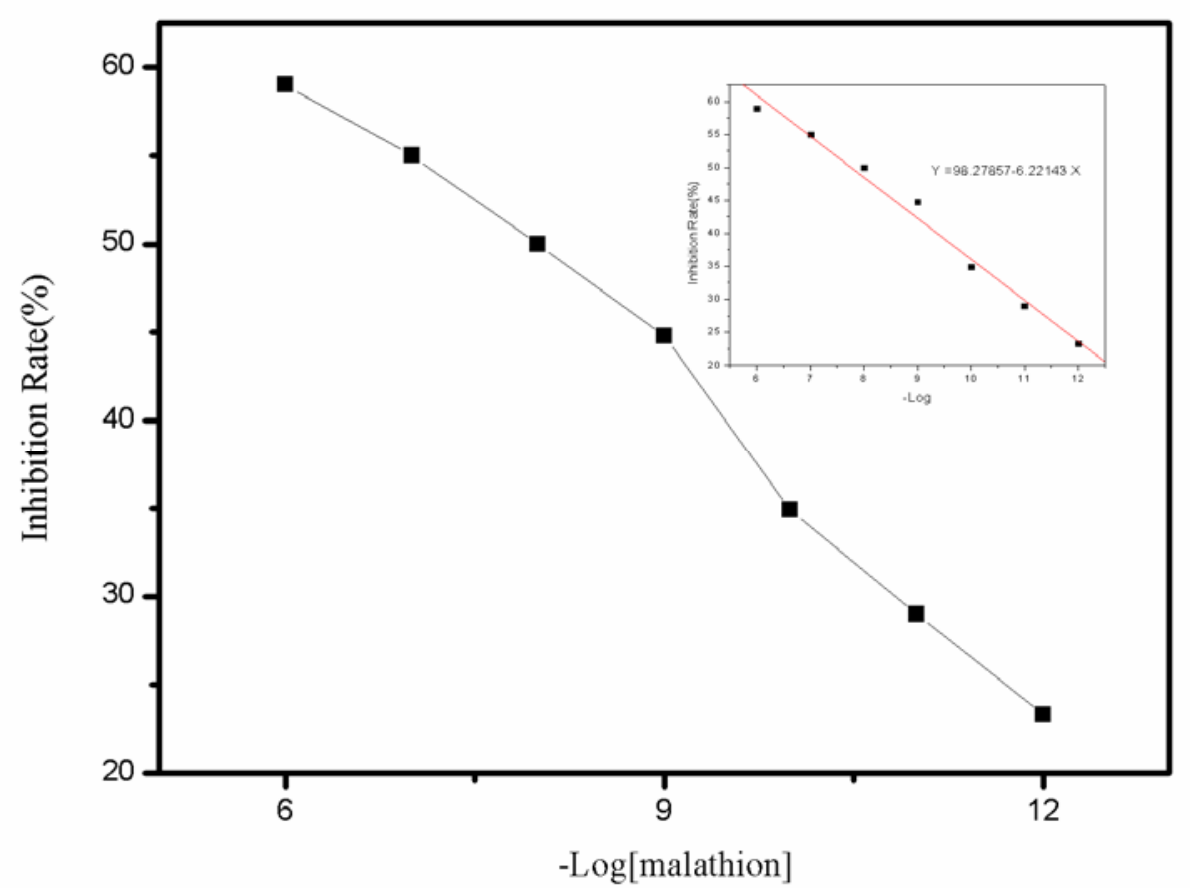

Fig. 9a-Relationship between enzyme inhibition rate and - $\log$ [malathion]. Inset: linearity of enzyme inhibition rate and $-\log [$ malathion] between the concentration range of 10-6 to $10-12 \mathrm{~g} \cdot \mathrm{L}-1$.

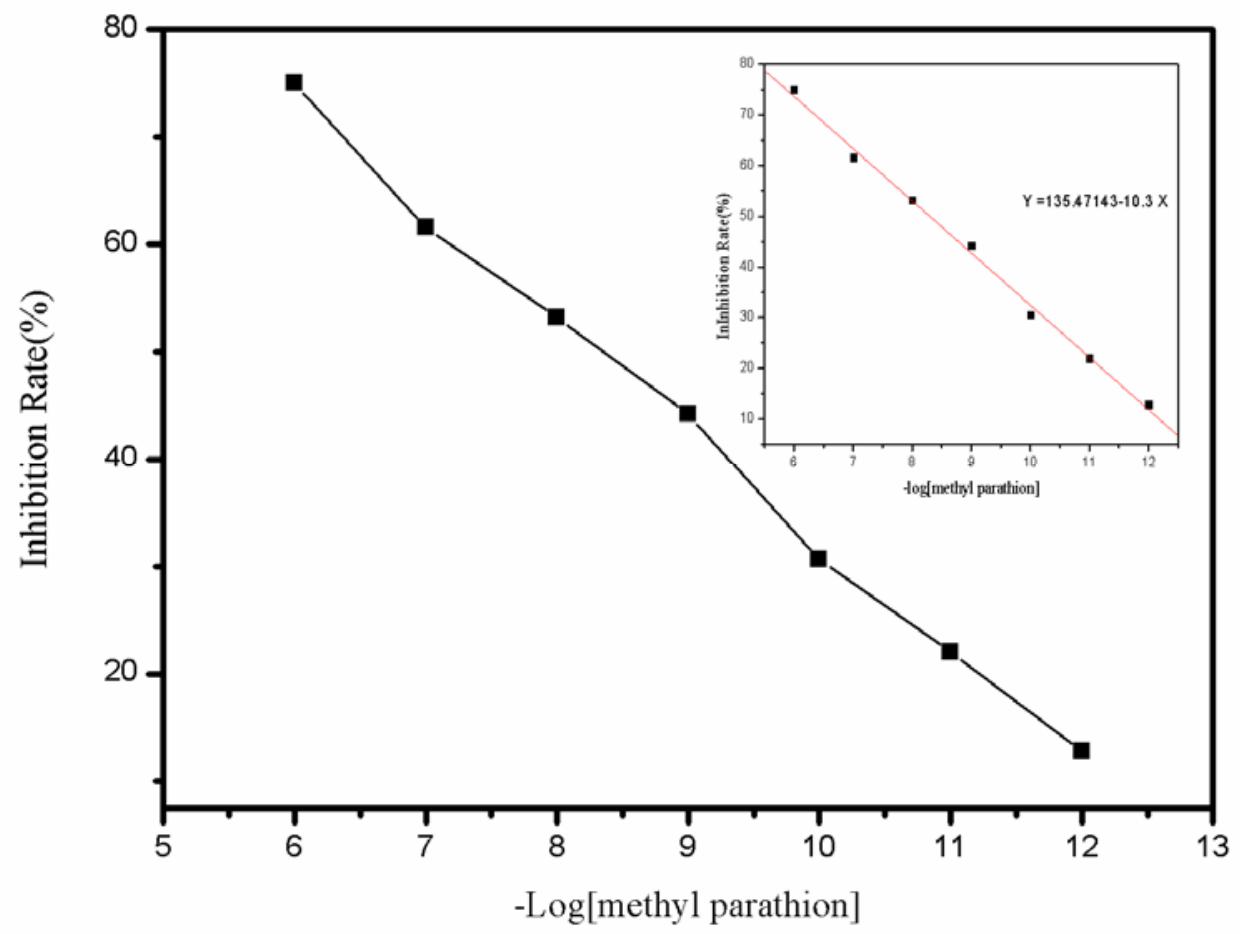

Fig. $9 \mathrm{~b}$ - Relationship between enzyme inhibition rate and -log[methyl parathion].

Inset: linearity of enzyme inhibition rate and $-\log [$ methyl parathion] between the concentration range of 10-6 to $10-12 \mathrm{~g} \cdot \mathrm{L}-1$.

Because the catalytic activity of AChE was inhibited resulting in a decline in current and the extent of the current decline was directly proportional to the concentration of the inhibitor. Measurement of organophosphorus pesticides was carried out in a two-step procedure. The first step involves in measuring the response of biosensor, when the substrate was added to the buffer and this value is corresponds to I0 (current before the inhibition of pesticide). In the second step the electrode was washed with the same buffer and was placed in the sample containing a known 
concentration of pesticide solution and measured the response, this second value corresponds to I1 (current after the inhibition of pesticide). An inhibition formula rate of $\mathrm{AChE}$ such as follows: ${ }^{33}$

$$
\% \text { Inhibition }=[\mathrm{I} 0-\mathrm{I} 1 / \mathrm{I} 0] \times 100
$$

When the substrate concentration was certain,the current was only related to the activity of the enzyme, so the pesticide concentration could be detected by measuring the reduction of response current. I0 was found to be $1.787 \mu \mathrm{A}$ for $5 \mathrm{U}$ activity of AChE, where I0 and I1 denoted the current in the absence and presence of organophosphorus pesticide, respectively. Fig. 9 (a.b) showed a good linearity between inhibition rates and $-\log [$ malathion] and $-\log [$ methyl parathion] in a concentration range of 10-6 to 10$12 \mathrm{~g} \cdot \mathrm{L}-1$.

A calculation equation for detection limit (LD) of OPs was given below: ${ }^{33}$

\section{$\mathrm{LD}=3 \mathrm{SB} / \mathrm{b}$}

$\mathrm{SB}$ is the standard deviation of the blank solution and $b$ is the slope of the analytical curve of regression equation as shown upper right of Fig. 9. It showed a good linear relation with the detection limit of $10-6$ to $10-12 \mathrm{~g} \cdot \mathrm{L}-1$ in PBS. Because of OPs inhibition was irreversible and the substrate concentration was certain, the inhibition ratio was linearly dependent on the $\log$ of the OPs concentration from 10-6 to 10$12 \mathrm{~g} \cdot \mathrm{L}-1$ in $\mathrm{PBS}$. The linear regression equations (malathion and methyl parathion, respectively) were $\mathrm{Y}=98.27857-6.22143 \mathrm{X}$ and $\mathrm{Y}=135.47143$ $10.3 \mathrm{X}$, and the correlation index were 0.9867 and 0.9962 , and the check out $(3 \mathrm{~S} / \mathrm{N})$ were $3.11 \times 10$ $13 \mathrm{~g} \cdot \mathrm{L}-1$ and $1.88 \times 10-13 \mathrm{~g} \cdot \mathrm{L}-1$. The difference in the detection limit was related with the structure of the chosen OPs. Most of OP pesticides had the phosphorothionate group $(\mathrm{P}=\mathrm{S})$ (e.g. malathion), which conferred hydrolytic stability to them. However, methyl parathion could be converted to oxons either in environment or in vivo, and then, becoming more reactive. 34 Thus, the calibration curve for malathion had poor linearity on the studied calibration range. Although $\mathrm{CV}$ was the most commonly used electrochemical approach and might serve as an additional confirmation in sensitive detection of malathion, meanwhile, malathion might be less responsive to $\mathrm{CV}$ than other pesticides. Comparing with the national standards which were LD $=4.3 \times 10-9 \mathrm{~g} \cdot \mathrm{L}-1$ and $\mathrm{LD}=2.8 \times 10-9 \mathrm{~g} \cdot \mathrm{L}-1$ for malathion and methyl parathion, the detection limits all raised about 10000 times. The analytical performance was compared with other reported biosensors, and the results were summarized in Table 1 . All the results showed that this biosensor exhibited low detection limit and wider linear range.

Table 1

Comparisons of the proposed biosensor for detection of OPs with other biosensors

\begin{tabular}{|c|c|c|c|}
\hline Electrode & Linear Range & Detection Limit & Ref. \\
\hline AChE/CNT-NH2/GCE & $\begin{array}{l}0.2-1 \mathrm{nM} \\
1-30 \mathrm{nM}\end{array}$ & $0.08 \mathrm{nM}$ & 36 \\
\hline $\begin{array}{l}\text { AChE/SWCNT-Co } \\
\text { phtalocyanine/SPE }\end{array}$ & $5-50 \mathrm{ppb}$ & $3 \mathrm{ppb}$ & 37 \\
\hline AChE/PANI /ssDNA-SWCNT/Au & $10-11-10-6 \mathrm{M}$ & $10-12 \mathrm{M}$ & 38 \\
\hline AChE/3-APTES/cSWCNT/FG & $20-80 \mathrm{nM}$ & $15 \mathrm{nM}$ & 39 \\
\hline AChE-SF/MWCNTs/GCE & $3.5 \times 10-6-2.0 \times 10-3 \mathrm{M}$ & $5.0 \times 10-7 \mathrm{M}$ & 40 \\
\hline AChE-Fe3O4NPs/c-MWCNTs/ITO & $0.1-70 \mathrm{nM}$ & $0.1 \mathrm{nM}$ & 41 \\
\hline AChE/MWCNTs-Au-CHIT/GCE & $\begin{array}{l}1.0-1000 \mathrm{ng} / \mathrm{mL} \\
2-15 \mu \mathrm{g} / \mathrm{mL}\end{array}$ & $0.6 \mathrm{ng} / \mathrm{mL}$ & 42 \\
\hline
\end{tabular}


Table 2

Recovery tests of malathion in tap water, purified water and Chinese cabbage

\begin{tabular}{llll}
\hline Sample & Added amount(g L-1) & Measured amount(g L-1) & Recovery (\%) \\
\hline \multirow{2}{*}{ Tap water } & $10-10$ & $1.04 \times 10-10$ & 104 \\
& $10-8$ & $0.96 \times 10-8$ & 96 \\
Purified water & $10-10$ & $0.97 \times 10-10$ & 97 \\
& $10-8$ & $1.05 \times 10-8$ & 105 \\
Chinese cabbage & $10-10$ & $0.97 \times 10-10$ & 97 \\
& $10-8$ & $1.03 \times 10-8$ & 103 \\
\hline
\end{tabular}

\subsection{Repeatability of the biosensor}

The repeatability was confirmed by evaluating the relative standard deviation (RSD) of sensor response for five days continuous measurements with the same electrode in the presence of 10$12 \mathrm{~g} \cdot \mathrm{L}-1$ malathion in PBS containing $2 \mathrm{mM}$ ATCl. The RSD of inter-day was found to be $4.59 \%$, which indicated this method with simple steps displayed a high repeatability.

\subsection{Real samples analysis with the proposed biosensor}

Finally, the potential practical application of the AChE/DAR/PB-SWCNTs/DAR/P-ASBA/GCE biosensor was evaluated by recovery test that performed by adding malathion into tap water, purified water and Chinese cabbage. The recovery test was conducted by using the standard addition method, and the results were summarized in Table 2. From Table 2, the results showed that the values of the recovery were in the range of $96 \%$ to $105 \%$. These further tests indicated a reliable OPs detection in real samples with the assembled biosensor. Consequently, the AChE/DAR/PBSWCNTs/DAR/P-ASBA/GCE biosensor displayed significant potential for practical application.

\section{EXPERIMENTAL}

\section{Chemical reagents and materials}

Acetylcholinesterase (AChE, 1000 units/mg), acetylthiocholine chloride (ATCl, $\geq 99 \%$ ), organophosphorus pesticide (malathion and methyl parathion, $500 \mu \mathrm{g} / \mathrm{mL}$, respectively), paraformaldehyde (POM, $\geq 95 \%$ ) and Variamine Blue RT Salt $(\geq 95 \%)$ were purchased from Sigma-Aldrich. Carboxylfunctionalized single-walled carbon nanotubes (SWCNTs, $\geq 95 \%$, content of carboxylic acid group $2.73 \mathrm{wt} \%$, diameter $1-2 \mathrm{~nm}$, length 1-3 $\mu \mathrm{m}$ ) were purchased from Chengdu Organic Chemicals Co. Ltd., Chinese Academy of Sciences Corporation. Diazo-resin (DAR) was synthesized according the literature. ${ }^{25}$ Phosphate buffer solution (PBS, 0.1 M, pH 5.5) containing $\mathrm{K}_{2} \mathrm{HPO}_{4}$,
$\mathrm{KH}_{2} \mathrm{PO}_{4}$ and $0.1 \mathrm{M} \mathrm{KCl}$ was employed as the supporting electrolyte. Except additional instructions, reagents were of analytical reagent grade and used as received solvents. Aqueous solutions were prepared with deionized water. All the electrochemical measurements were carried out at room temperature.

\section{Apparatus and instruments}

Electrochemical measurements were performed on CHI660E electrochemical workstation $(\mathrm{CH}$ Instruments, Inc, USA) with a standard three-electrode system, employing a platinum sheet as the counter electrode, a saturated calomel electrode (SCE) as the reference electrode and a modified glassy carbon electrode (GCE) as the working electrode. The electrical impedance spectroscopy (EIS) was carried out in $\mathrm{pH}$ 5.5 PBS containing $5 \mathrm{mM} \mathrm{K} \mathrm{K}_{3}\left[\mathrm{Fe}(\mathrm{CN})_{6}\right] / \mathrm{K}_{4}\left[\mathrm{Fe}(\mathrm{CN})_{6}\right]$ and $0.1 \mathrm{M} \mathrm{KCl}$. UV irradiation was performed using a UV lamp (365 nm, WDH-2048, Shanghai Chi Tang Instrument Co., Ltd.). UV-vis spectroscopy was recorded on a TU-1901 UVvis spectrophotometer (PUXI Co., Beijing).

\section{Preparation of PB-SWCNTs}

The PB-SWCNTs compound was synthesized according to the literature. ${ }^{27}$ Pristine SWCNTs were suspended in a $3: 1$ mixture of concentrated sulfuric and nitric acid. The carboxylated SWCNTs was obtained by applying ultrasonic agitation for $1 \mathrm{~h}$. The COOH-SWCNTs was washed with deionized water after $10000 \mathrm{r} / \mathrm{min}$ centrifuged. PB was prepared by mixing a certain concentration $\mathrm{Fe}(\mathrm{NO} 3) 3(\mathrm{pH}=1)$ and $\mathrm{K}_{4}\left[\mathrm{Fe}(\mathrm{CN})_{6}\right]$ aqueous solution with a briefly stirred. After that, the dark blue precipitates were gained, then washed with deionized water, and dried at room temperature. Next PB powders was added to SWCNTs aqueous solution with vigorous stirring for $10 \mathrm{~h}$ and dried at $50^{\circ} \mathrm{C}$, the PB-SWCNTs compounds were obtained. The prepared PB-SWCNTs compounds were stored in a dark bottle at room temperature until further use.

\section{Preparation of DAR(diazo-resin)}

Approximately $6.6 \mathrm{~mL}$ solution of sulfuric acid was put into a $50 \mathrm{~mL}$ conical flask which was in an ice bath. The following steps were all to avoid light. When the temperature of conical flask dropped to $0-5{ }^{\circ} \mathrm{C}$, the Variamine Blue RT Salt ( $3 \mathrm{~g}, 10 \mathrm{mmol}$ ) were added to the $50 \mathrm{~mL}$ conical flask containing sulfuric acid. Appropriate amount of paraformaldehyde $(0.36 \mathrm{~g}, 12 \mathrm{mmol})$ were added to the $50 \mathrm{~mL}$ conical flask at $0-5{ }^{\circ} \mathrm{C}$ constantly stirring $3 \mathrm{~h} . \mathrm{ZnCl} 2(2 \mathrm{~g})$ were dissolved in $12 \mathrm{~mL}$ deionized water and placed in $4{ }^{\circ} \mathrm{C}$ for later use. $\mathrm{ZnCl} 2$ 
solution was added to the reaction system, and the mixed system was placed in the refrigerator overnight at $4{ }^{\circ} \mathrm{C}$. In the second day, the mixed solution was filtrated until the sediment layer cracked but did not turn black. Then the product was dissolved in $60 \mathrm{~mL}$ ethanol absolute and stirred. $60 \mathrm{~mL}$ diethyl ether was added to the mixture to extract solidity and the solidity was washed with approximately $100 \mathrm{~mL}$ diethyl ether twice. The solid product of yellow DAR was dried at Vacuum overnight and stored in the refrigerator.

\section{Fabrication on GCE}

The GCE was firstly polished with 0.3 and $0.05 \mu \mathrm{m}$ alumina slurry and rinsed with deionized water. Then the GCE was successively sonicated in ethanol and deionized water for $5 \mathrm{~min}$ and dried at room temperature. A clean GCE through electrochemical modification functionalized with P-ABSA to yield a sulfonic-functionalized monolayer ionic membrane. Based on previous literature, ${ }^{35}$ the electrochemical modified GCE was performed in $5 \mathrm{mM}$ P-ABSA solution containing $0.1 \mathrm{M} \mathrm{KCl}$ at scan rate $10 \mathrm{mVs}-1$ in potential range from 0.5 to $1.4 \mathrm{~V}$ until the current stabilized. After modified, the fabricated GCE was dried at room temperature. Then the P-ABSA-modified GCE continued to be modified with multilayer films of (DAR/PB-SWCNTs)n. Firstly the glassy carbon electrode (GCE) surface would be modified with negatively charged sulfurous acid groups by electrochemical modification P-ABSA. Secondly, the modified electrodes were immersed into $5 \mathrm{~mL}$ solution containing $0.3 \mathrm{mg} / \mathrm{mL}$ in DAR for 15 minutes and dried at room temperature. Thirdly the electrodes were put in $5 \mathrm{~mL}$ PB-SWCNTs solution $(0.1 \mathrm{mg} / \mathrm{mL})$ in 5 minutes rinsed with deionized water and dried at room temperature. Because DAR had positive charges, it would also be assembled with negatively charged from PB-SWCNTs to make PB-SWCNTs/DAR/P-ABSA/GCE. Then the modified electrodes were immersed in DAR solution for 15 minutes again. DAR was again in the form of electrostatic self-assembly adsorption onto PB-SWCNTs, forming DAR/PB-SWCNTs/DAR/P-ABSA/GCE. Finally, 5 $\mu \mathrm{L}$ solution (including $5 \mathrm{U} \mathrm{AChE}$ ) was picked up by transfer liquid gun and dispensed onto the modified electrodes surface. Then the electrodes were stood for 30 minutes, rinsed with deionized water and dried by nitrogen. Because AChE's isoelectric point $(\mathrm{pI}=5.6)$ was 5.6 with a negative charge, it was very easy to get the AChE/DAR/PB-SWCNTs/DAR/PABSA/GCE by electrostatic interactions. In order to improve the stability of ionic bond film, the UV lamp was used to irradiate electrodes (UV cross-linking) 30s to turn ionic bond into covalent bonds. The amino groups in DAR would react with the carboxyl groups of AChE, carboxyl groups of PBSWCNTs and sulfurous acid groups on the surface of the glassy carbon electrode to form covalent bonds. This would form a covalently attached multilayer nano biofilms and prepare a stable AChE electrochemical biosensors. The stepwise fabrication process of the AChE/DAR/PB-SWCNTs/DAR/P-ABSA/GCE biosensor is illustrated in Scheme 1.

\section{Electrochemical measurements}

The electrochemical measurements were performed with a three-electrode electrochemical workstation. The AChE/DAR/ PB-SWCNTs/DAR/P-ASBA/GCE sensing system as the working electrode was immersed in PBS solution $(0.1 \mathrm{M}, \mathrm{pH}$ $5.5)$ or $0.1 \mathrm{M} \mathrm{KCl}$ solution containing $5 \mathrm{mM} \mathrm{Fe}(\mathrm{CN}) 63-/ 4-$ at room temperature. The electrochemical measurements based on $\mathrm{CV}$ and EIS (at open circuit potential: $0.01-105 \mathrm{~Hz}$ of frequency range; $5 \mathrm{mV}$ of amplitude) modes were conducted. All electrochemical measurements were conducted repeatedly.

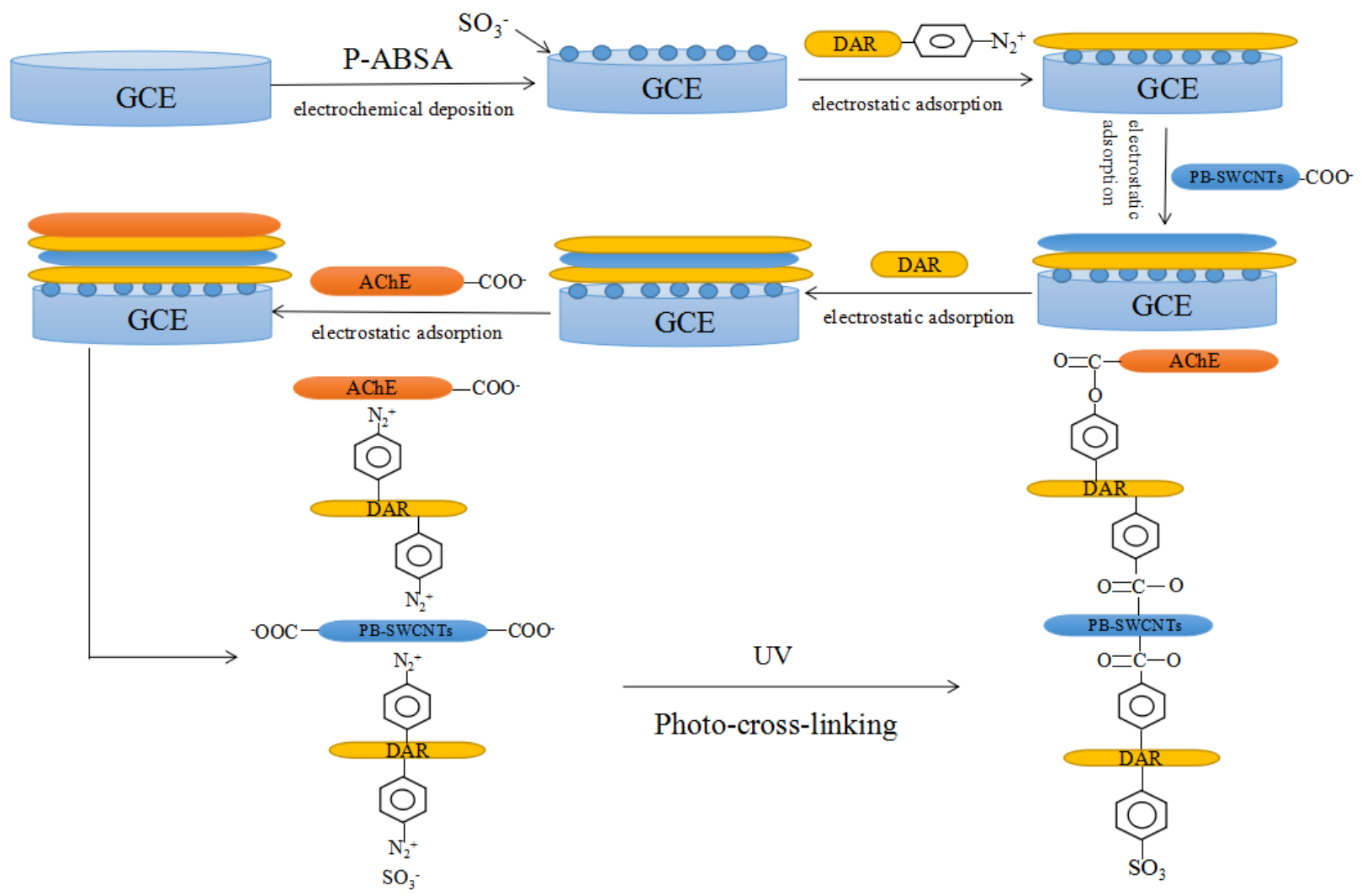

Scheme 1 - Schematic illustration for stepwise fabrication process of the biosensor. 


\section{Preparation of real samples}

The vegetable samples were manufactured by the following procedure. A sample of chopped vegetables $(10 \mathrm{~g})$ and $100 \mathrm{~mL}$ of methanol were stirred for $60 \mathrm{~min}$. The supernatant liquid was filtered through a filter paper and repeated twice. The filter was rinsed with $20 \mathrm{~mL}$ of methanol and evaporated in a rotary evaporator. The volume of the solution was reduced to about $1 \mathrm{~mL}$. The residue was dissolved in deionized water and made up to $10 \mathrm{~mL}$ with deionized water in a calibrated flask. For the analysis of tap water and purified water, samples were collected into $250 \mathrm{~mL}$ containers. Samples were filtered with filter paper and stored for no more than $24 \mathrm{~h}$ at $4^{\circ} \mathrm{C}$ in the dark.

\section{CONCLUSIONS}

A novel stable covalently attached multilayer films was successfully fabricated based on layerby-layer self-assembly technique. Experimental results showed that the PB-SWCNTs backbone acted as both the electron transfer facilitator and the low-potential electron transfer mediator. The biosensor showed an excellent detection limit for both malathion and methyl parathion in a wide linear range with good precision and reproducibility. The films also displayed good recovery in the analysis of real samples and thus had significant potential for practical application. Moreover, the storage stability of the biosensor revealed a high level of stability, indicating that strong covalent bond used to modify the electrode improved the stability of the biosensor compared with weak electrostatic force adsorption. It is anticipated that covalently attached multilayer assemblies could be used to fabricate stable enzyme biosensors in future research, and this method is suitable for the quantitative detection of trace OPs.

Acknowledgements. This paper was carried out at the "Northwest university research fund (Grant No. 338020015)" under Northwest university, and was financially supported by scientific research plan projects of Shaanxi education department (Grant No. 203010019).

\section{REFERENCES}

1. M. Tankiewicz, J. Fenik and M. Biziuk, TrAC, Trends Anal. Chem., 2010, 29, 1050-1063.

2. M. Eddleston, F. Worek, P. Eyer, H. Thiermann, L. V. Meyer, K. Jeganathan, M. H. R. Sheriff, A. H. Dawson and N. A. Buckley, QJM-Mon. J. Assoc. Phys., 2009, 102, 785-792.

3. A. Kamel, C. Byrne, C. Vigo, J. Ferrario, C. Stafford, G. Verdin, F. Siegelman, S. Knizner and J. Hetrick, Water Res., 2009, 43, 522-534.

4. X. Wang, X. Qiao, Y. Ma, T. Zhao and Z. Xu, J. Agric. Food Chem., 2013, 61, 3821-3827.

5. L. Wu, Y. Song, M. Hu, H. Zhang, A. Yu, C. Yu, Q. Ma and Z. Wang, Food Chem., 2015, 176, 197-204.

6. L.-F. Alfonso, G. V. Germán, P. C. María del Carmen and G. Hossein, Chemosphere, 2017, 166, 292-299.
7. B. Y. Fosu-Mensah, E. D. Okoffo, G. Darko and C. Gordon, Environ. Syst. Res., 2016, 5, 1-12.

8. K. Pozo, Y. Llanos, V. H. Estellano, S. Cortés, H. Jorquera, L. Gerli, K. Pozo, F. Encina, R. Palma and S. Focardi, Atoms. Pollut. Res., 2016, 7, 706-710.

9. Z. Chishti, S. Hussain, K. R. Arshad, A. Khalid and M. Arshad, J. Environ. Manage, 2013, 114, 372-380.

10. M. Farajzadeh, M. Bahram, A. Morteza, S. Vardast, K. Mohammad, M. Bamorowat and A. Mehdi, Microchim. Acta, 2011, 172, 465-470.

11. L. Vaclavik, M. Vaclavikova, T. H. Begley, A. J. Krynitsky and J. I. Rader, J. Agric. Food Chem., 2013, 61, 4822-4830.

12. T. Zhou, X. Xiao and G. Li, Anal. Chem., 2012, 84, 58165822.

13. W. Tang and J. Wu, Anal. Methods, 2014, 6, 924-929.

14. C. Zhai, X. Sun, W. Zhao, Z. Gong and X. Wang, Biosens. Bioelectron., 2013, 42, 124-130.

15. G. Liu and Y. Lin, Anal. Chem., 2006, 78, 835-843.

16. Y. Li, Y. Bai, G. Han and M. Li, Sens. Actuators B Chem., 2013, 185, 706-712.

17. S. Cevik, S. Timur and U. Anik, RSC ADV., 2012, 2, 42994303.

18. H. Zhao, X. Ji, B. Wang, N. Wang, X. Li, R. Ni and J. Ren, Biosens. Bioelectron., 2015, 65, 23-30.

19. P. M. Ajayan, Chem. Rev., 1999, 99, 1787-1800.

20. S. Iijima, Nature, 1991, 354, 56-58.

21. F. Xi, L. Liu, Z. Chen and X. Lin, Talanta, 2009, 78, 10771082.

22. W. Li, R. Yuan and Y. Chai, Talanta, 2010, 82, 367-371.

23. G. Fu, X. Yue and Z. Dai, Biosens. Bioelectron., 2011, 26, 3973-3976.

24. Y. Miao, J. Chen, X. Wu and J. Miao, Colloids Surf. A, 2007, 295, 135-138.

25. J. Zhai, Y. Zhai, D. Wen and S. Dong, Electroanalysis, 2009, 21, 2207-2212.

26. P. R. Somani and S. Radhakrishnan, Mater. Chem. Phys., 2003, 77, 117-133.

27. Y. Zhang, Y. Wen, Y. Liu, D. Li and J. Li, Electrochem. Commun., 2004, 6, 1180-1184.

28. L. Qian and X. Yang, Colloids Surf. A, 2006, 278, 123-128.

29. J. Zhang, J.-K. Lee, Y. Wu and R. W. Murray, Nano Lett., 2003, 3, 403-407.

30. M. Shim, N. Kam, R. Chen, A. Y. Li and H. Dai, Nano Lett., 2002, 2, 285-288.

31. P. Diao, Z. Liu, B. Wu, X. Nan, J. Zhang and Z. Wei, Chem. Phys. Chem., 2002, 3, 898-991.

32. A. Afkhami, F. Soltani-Felehgari and T. Madrakian, Electrochim. Acta, 2013, 103, 125-133.

33. S. Firdoz, F. Ma, X. Yue, Z. Dai, A. Kumar and B. Jiang, Talanta, 2010, 83, 269-273.

34. S. B. Bharate, J. M. Prins, K. M. George and C. M. Thompson, J. Agric. Food Chem., 2010, 58, 8460-8466.

35. X. Li, Y. Wan and C. Sun, J. Electroanal. Chem., 2004, 569, 79-87.

36. G. Yu, W. Wu, Q. Zhao, X. Wei and Q. Lu, Biosens. Bioelectron., 2015, 68, 288-294.

37. A. N. Ivanov, R. R. Younusov, G. A. Evtugyn, F. Arduini, D. Moscone and G. Palleschi, Talanta, 2011, 85, 216-221.

38. S. Viswanathan, H. Radecka and J. Radecki, Biosens. Bioelectron., 2009, 24, 2772-2777.

39. S. P. Sharma, L. N. S. Tomar, J. Acharya, A. Chaturvedi, M. V. S. Suryanarayan and R. Jain, Sens. Actuators B Chem., 2012, 166-167, 616-623.

40. R. Xue, T.-F. Kang, L.-P. Lu and S.-Y. Cheng, Appl. Surf. Sci., 2012, 258, 6040-6045.

41. N. Chauhan and C. S. Pundir, Electrochim. Acta, 2012, 67, 79-86.

42. D. Du, M. Wang, J. Cai, Y. Qin and A. Zhang, Sens. Actuators B Chem., 2010, 143, 524-529. 
